\title{
A EDUCAÇÃO COMO ARTE DOS ENCONTROS
}

Leonardo Rangel dos Reis ${ }^{1}$

\section{INTRODUÇÃO}

A cosmovisão antropocêntrica, perspectiva teórica/ontológica que reafirma a dualidade natureza versus cultura e a superioridade do segundo termo da relação, é em seu bojo, a priorização da mente e de seus processos de racionalização instrumentais, em detrimento dos outros processos. Ela é criticada pelas epistemologias que partem do mundo da vida que, a partir da crítica à episteme da representação, propõem uma epistemologia restaurativa do homem e da natureza, da materialidade do mundo e de suas formas criativas.

Propomos, para usar um termo de Tim Ingold (2015), perceber a atenção, como forma de manifestação da consciência, no mesmo nível de importância epistêmica da significação. A atenção às presenças, aos movimentos e aos conhecimentos são operações do estar vivo. O estar vivo atento para a rematerialização de um mundo que se desmaterializou por causa da instauração da razão metafísica e semiótica geradora de uma realidade em que os significados perderam-se em camadas de linguagem, muitas vezes, já estéreis e áridas. Então, para que haja a possibilidade de novos mundos possíveis, fazem-se necessários outros movimentos existenciais que tragam linhas de fuga e linhas de força propositivas e transformadoras.

Em torno desta crítica, a educação e os agenciamentos curriculares, bem como as demandas formativas que se depreendem desses processos, poderá, quiçá, potencializar as instâncias ontológicas, ecológicas, epistemológicas, existenciais etc., nos ajudando na composição/configuração de novos mundos possíveis. Instâncias estas que, notadamente nos âmbitos da ontologia e ecologia, que ao carregarem em si a condição de problematização ao que está posto, ao estabelecido, aguçam condições propositivas e trans-formadoras.

A educação, do ponto de vista da epistemologia etnocêntrica, é um empreendimento cultural que articula repertórios de saberes e conhecimentos humanos de controle e uso da natureza, como se habitássemos a cultura independente da natureza, em que esta é vista como externalidade. Nessa perspectiva, a educação perde sua potência e suas possibilidades de linhas de força.

\footnotetext{
${ }^{1}$ Professor de Sociologia, do Departamento de Sociologia, Psicologia e Pedagogia - DSPP, do Instituto Federal da Bahia, Campus Salvador. leonardorangelrreis@gmail.com
} 
Nesse sentido, a educação pode tornar-se, ao mesmo tempo, uma iniciativa que ativaria as tão adormecidas, dimensões críticas e criativas, que são potentes mobilizadoras/criadoras de existências.

Para dar um exemplo de linhas de força criadoras de existência e novos acoplamentos, podemos trazer as transposições de limites entre o humano e o animal, no modo de relação de determinados animais com seus tutores. A relação entre o homem e o cão tem sido reconfigurada. Inclusive hoje não se fala mais em "dono", mas em tutor. Humanos e não humanos (cães, gatos, pássaros, etc.) estabelecem malhas de interações significativas nas quais há afetações mútuas. Tais configurações criam novas formas de habitar o social, forçando e transformando os laços que definiam os sentimentos intraespécie. Assim, as novas sensibilidades expandem as experiências familiares para incluir, como um de seus membros, seres de outras espécies.

Segundo Maturana (2001), quando saímos da racionalidade conceitual e vamos para a experiência dos sentimentos: de amor, afeto e da capacidade de sentir a importância da vida através do amor, como fazem muitos cães, nos conectamos com a força da autopoiese. A aprendizagem não é um ato puramente cognitivo, neutro, linear.

Uma saída possível é o ultrapassamento das perspectivas que tomam os fenômenos de ensinoaprendizagem como neutros, sem fazer referência aos seus contextos, nem aos jogos de poderes que estão presentes neles, pois, fazendo isso, tal escola não consegue compreender a educação nem como instância crítica, nem como criadora, visto que, de acordo com tal perspectiva, ela se encontra apenas envolvida com a reprodução do que já está posto2. Um dos grandes paradigmas aqui é Durkheim na França e Bobbitt nos EUA.

Apesar da inegável importância do movimento da Escola Crítica, não se pode deixar de pontuar que, na ânsia da crítica, não se consegue compreender os movimentos criativos de autonomia e inovação que circulam ou podem circular pelos espaços da escola. Os autores mais representativos dessa visão são os franceses: Althusser e Bourdieu. Porém, ao fazer isso, esses autores acabam

\footnotetext{
2 É bastante destacado nos estudos da área de educação, não sem um certo reducionismo, que os chamados modelos tradicionalistas, na busca da neutralidade e, consequente, desconsideração dos contextos e jogos de poderes passam ao largo da crítica e da criatividade. A crítica a este modelo de escola foi fortemente evidenciada pelo movimento da Escola Crítica que desmascara os sentidos da pretensa neutralidade apontando com demasiada ênfase a escola como instância reprodutora. Esse movimento de mera reprodução é apenas uma tipologia ideal, um exagero, porque, na realidade, às coisas se apresentam de modo bem mais complexo. Até podemos especular que não existe um estado em que a reprodução se torna completamente autocentrada, dirigindo-se a si mesma, sem necessidade do seu oposto. Veremos isso adiante, quando tocarmos na relação da diferença com a repetição. Em tal contexto, poder-se-á conjecturar que a repetição figurará o eterno retorno da diferença e não seu oposto (DELEUZE, s/n).
} 
estrangulando a importância da potência criativa, que constitui fonte potente de trans-formação e que, inegavelmente, circula nesses espaços.

\section{O DUPLO ENLACE DA EDUCAÇÃO}

É por isso que a educação e seus objetos mais realçados podem ser compreendidos através de um duplo enlace: criação e repetição. Trata-se de mostrar como os currículos e as formações vão se constituído através de relações tensivas, entre os circuitos dos processos criativos (operadores da mudança) e os movimentos dos processos de repetição (operadores da estabilidade). Tanto a estabilidade quanto a mudança são necessários, pois uma proposta toda calcada no operador da mudança terá muita dificuldade em se manter, em se deixar de pé. Já as propostas com pouca margem de mudança poderão facilmente se fossilizar e estrangular toda e qualquer tentativa de inovação, de criação. Assim, precisamos desse duplo movimento na composição das propostas curriculares e formativas, na educação, uma vez que eles existem em todo acontecer.

De tal modo, pode-se dizer que a educação é simultaneamente um projeto crítico e construtivo, porque, além de ajudar no movimento de problematização ao que está posto, tido como normal, não poderá ficar apenas nesse registro, sob-risco de resvalar em processo niilista, que opta por demolir o que está dado; sem planos, nem pretensão de colocar nada em seu lugar ${ }^{3}$. Ao fazer isso, a educação contribui para agudizar a crise de referências que já se encontra em estado avançado e faz parte dos nossos cotidianos há muitas décadas. Então, ela configura-se inegavelmente como instância propositiva, capaz de criar e interferir na realidade em que ela também ajuda a compreender. O que estará daqui em diante em jogo é o resgate de campos de virtualidade "futuristas" e construcionistas, pois

o inconsciente permanece agarrado em fixações arcaicas apenas enquanto nenhum engajamento o faz projetar-se para o futuro. Essa tensão existencial operar-se-á por intermédio de temporalidades humanas e não-humanas. Entendo por estas últimas o delineamento ou, se quisermos, o desdobramento de devires animais, vegetais, cósmicos, assim como de devires maquínicos, correlativos da aceleração das revoluções tecnológicas e informáticas (é assim que vemos desenvolver-se a olhos vistos a expansão prodigiosa de uma subjetividade assistida por computador). A isso acrescentemos que convém não esquecer as dimensões institucionais e de

\footnotetext{
${ }^{3}$ Estamos nos referindo apenas a um traço do niilismo, porque o mesmo é muito mais complexo e nuançado. Só estamos chamando à atenção disso, pois costuma-se acentuar que o período de crise de referenciais em que vivemos, assemelhase ao estado do niilismo. Sob esse prisma, isso só pode ser parcialmente verdadeiro.
} 
classe social que presidem a formação e a "teleguiagem" dos indivíduos e grupos humanos" (GUATTARI, 1990, p. 20-21).

De tal modo, a educação está enredada com a compreensão de modo específico, visto que sua concepção está envolvida em solo pragmático. É um envolvimento que compreende e altera, ou melhor dizendo: é um envolvimento que altera na medida em que vai compreendendo.

A educação, enquanto envolvimento que compreende e altera, torna-se um movimento crítico e pragmático. É por isso que ela sempre se envolve em questões que dizem respeito à alçada da ética. Porque ela também está implicada em movimentos que dizem respeito à trans-formação, a possibilidades de alteração ao que está posto, mesmo que tal movimento seja sufocado ou não seja visto.

Porque, saibamos ou não, os(as) professores(as) sempre estão implicados com as possibilidades de trans-formação dos territórios existenciais dos(as) estudantes e dos demais atores(atrizes) que compõem os cenários dos estabelecimentos de ensino.

Então, nossa responsabilidade ética é inegável, sobretudo por estarmos ligados às possibilidades de mudança ou repetição das paisagens existenciais daqueles que se encontram, de diversos modos, aos nossos cuidados. Aliás, não podemos esquecer de que o cuidado é um dos princípios basilares da ética, desde a antiguidade.

\section{CUIDADO COM A FORMAÇÃO E COM O CURRÍCULO}

Ao nos colocarmos no amparo das artes do cuidado, compreendemos que nossa atitude em relação ao outro certamente irá afetá-lo, sobretudo pelo fato do(a) professor(a) ter todo um respaldo e legitimidade para dizer e fazer o que caracterizam a sua prática docente. Geralmente, o que é dito ou feito não é tido/visto de forma gratuita, mas potencializado pelo status e pelo lugar conferidos ao docente em cada sociedade.

Mas, independentemente do papel atribuído ao(à) professor(a), este sempre está comprometido com a existência de outro(s), que encontram-se sob sua responsabilidade, em momentos e locais definidos. Assim, podemos dizer que o docente sempre está envolvido numa composição dos encontros.

Logo, o(a) docente, ao compreender, interfere e torna-se responsável, justamente na medida em que é partícipe dos processos de alteração e/ou repetição dos territórios existenciais de outrem. É 
por isso que sua prática está envolta nas artes do cuidado. Aqui, não devemos nos esquecer de que o próprio descuido pode ser considerado como falta ou deszelo de cuidado.

Portanto, pelo caráter da sua atividade, o cuidado manifesta-se prioritariamente nas possibilidades de encontro que são criadas. É por isso que devemos abusar da preposição com, porque ela nos informa que somos na dependência de outro(s). E, em relação à profissão docente, isso se torna ainda mais evidente, visto que esse profissional só exerce sua atividade com a "presença" do(a) estudante. Assim, temos que sua atividade só existe em relação. É através do compartilhar com o(a) estudante que seu exercício se forja. Não iremos entrar nas "nuances da presença", que foram intensificadas, sobretudo com o desenvolvimento das tecnologias de informação e comunicação e com a emergência da educação a distância. Basta ter em mente que o(a) docente que trabalha com esse tipo de educação, também tem em mira o outro. Ele(a) fala para uma audiência que não se encontra presente face a face, porque não está no mesmo espaço físico, mas pode estar presente enquanto projeção, virtualidade, como possibilidade que nos abre ao encontro. Aqui, temos as chamadas formas síncronas e assíncronas de interação.

\section{ENCONTROS E POTÊNCIAS DE VIDA}

A grande diversidade de modos de vida, liberada pelo processo de fragmentação dos laços de pertença, encontra-se em constante risco de ser sequestrada pelas codificações do mercado. Então, a possível liberdade que teríamos, com o fim dos grandes sistemas representativos e das metanarrativas, acabam sendo desviadas das possibilidades de potencialização da vida, em seus mais diversos aspectos, porque ficam demasiadamente atreladas às demandas da economia e das aporias do progresso. Com isso, as formas de aniquilação assumem dimensões planetárias; e "o deserto, fim e meio da civilização, designa essa figura trágica que a modernidade substitui à reflexão metafísica sobre o nada" (LIPOVETSKY, 2005, p. 17). Ainda sobre o deserto, o autor nos diz (2005, p. 18):

\footnotetext{
O mais estranho é que ele ocupa em silêncio a existência cotidiana, a sua e a minha, no coração das metrópoles contemporâneas. Um deserto paradoxal, sem catástrofes, sem tragédia ou vertigem, que cessou de se identificar com o nada e com a morte: não é verdade que o deserto induz à contemplação de crepúsculos mórbidos.
}

Com isso, os riscos se multiplicam, porque perdemos em segurança e também corremos o risco de nos enveredar na visada individualista, que remeteriam os distintos processos de subjetivações, ao prisma solipsista, e nos faria esquecer “de que não somos 'sujeitos' e sim 'sendos', 
parte integrante de um real em constante mutação" (UNGER, 2001, p. 42). Por isso que uma das características marcantes das nossas sociedades é justamente o fato delas operarem através de um sistema misto, não apenas disciplinar, mas agora as disciplinas e os controles. Logo, podemos dizer que todo fenômeno que gravita em torno dos saberes e dos poderes passa, ou passará em breve, por uma série de mutações, alterando sua dinâmica sob um dos signos da fluidez e da transitoriedade. Uma vez que entramos no contexto de intensificação da política da vida, ou seja, da biopolítica, momento em que "o biológico reflete-se no político" (FOUCAULT, 1988, p. 134), em que "o fato de viver [...] cai, em parte, no campo de controle do saber e de intervenção do poder" (Ibid.).Nesse contexto, passa a ser "sobre a vida e ao longo de todo o seu desenrolar que o poder estabelece seus pontos de fixação; a morte é o limite, o momento que lhe escapa; ela se torna o ponto mais secreto da existência, o mais “privado"” (FOUCAULT, 1988, p. 130).

Com isso, podemos dizer que a atual revolução verdejante é uma crise multifacetada, que nos coloca na condição de desterramento e vulnerabilidade, onde o deserto torna-se um dos mais representativos lócus do nosso atual estar no mundo. No entanto, a figura do deserto pode ser compreendida não apenas em sua acepção de carência ou negatividade, porque ele também figura como "lugar que contém em si múltiplas possibilidades de renovação e virtualidades de criação" (UNGER, 2001, p. 57).

Então, através dos movimentos abertos pelas trilhas no/do deserto, podemos tratar sobre a imperiosidade da vida e evidenciar como ela sempre extrapola ou soçobra toda tentativa de enquadramento antropológico do mundo. Com isso, teremos de resgatar a complexidade, beleza e dinâmica sobre os sentidos de estarmos sempre imersos nos emaranhados compostos da vida. Sobretudo porque os seres humanos sempre estão implicados na criação de linhas. Isso ocorre onde quer que eles estejam, aonde quer que eles vão (INGOLD, 2015). As linhas possuem toda relação com o movimento. Elas só podem ser compreendidas através deles. E, sempre que fios se transformam em pistas, superfícies se formam. Quando as pistas se transformam em linhas, as superfícies desaparecem. Por isso, a linha é sempre movimento e crescimento, seja ela um fio tecido ou uma pista escrita (INGOLD, 2015). Com isso, precisamos, com urgência, aprender a percorrer as linhas que ajudam a compor os emaranhados da vida.

Aqui, de alguma forma, o currículo está sendo enviado aos seus primórdios à sua semântica, pois um dos seus sentidos originários diz respeito ao caminhar, ao percorrer, ou seja, aos rastros e linhas deixados por algo que percorre, que transforma seus movimentos em caminhos. Caminhos de vida! 
Assim, compreendemos que uma das formas de liberarmos a diversidade de modos de vida, na atual aridez, no sentido moderno, que nos encontramos, é resgatar e/ou problematizar a potência dos movimentos que se dão através das possibilidades de encontros, pois o encontro não ocorre apenas entre duas pessoas. Nós nos mobilizamos sempre em relação a um mundo que se encontra sempre em devir. Que se apresenta através de ambientes sempre vazados. Assim, a educação pode ser compreendida como possibilidades de se criar encontros, uma arte dos encontros. Já o currículo pode ser concebido como a potência responsável pelo crescimento dos encontros. Ele pressupõe itinerários, movimentos que se desdobram em um plano, um lugar. Com isso, o problema da educação se desloca, porque ela própria torna-se uma arte da composição, visto que, como assevera Tadeu (2002, p. 55), agora, o que interessa "é saber quais composições são feitas e quais composições podem ser feitas e se elas são boas ou más ${ }^{4}$, do ponto de vista da potência de agir. Passar da formação para a composição, do desenvolvimento para a combinação, da organização para o agenciamento".

O encontro, pensado de forma pragmática, não utilitarista, nem antropocêntrica, pode ser considerado como o fundamento da interação, na medida em que podemos pensar com Deleuze (2003, p. 26) e seu intercessor Proust, que: "Ser sensível aos signos, considerar o mundo como coisa a ser decifrada é, sem dúvida, um dom. Mas esse dom correria o risco de permanecer oculto em nós mesmos se não tivéssemos os encontros necessários; e esses encontros ficariam sem efeito se não conseguíssemos vencer certas crenças". Assim, poderíamos dizer com ele que o que nos força a pensar é justamente o encontro. Nesse sentido, o próprio signo torna-se um objeto desse encontro, assim: "a criação, como gênese do ato de pensar, sempre surgirá dos signos. A obra de arte não só nasce dos signos como os faz nascer" (DELEUZE, 2003, p. 92). Ainda é preciso dizer que toda criação, toda produção, parte da impressão, pois "apenas ela reúne em si o acaso do encontro e a necessidade do efeito, violência que ela nos faz sofrer" (DELEUZE, 2003, p. 140).

Os encontros podem ser bons ou ruins. Inspirado em outro intercessor, o Espinosa, Deleuze (1981), dessa vez, nos diz que o encontro é bom quando ele potencializa a vida e nos traz alegria; e ruim quando leva à tristeza, a um decréscimo da potência. Porém, é importante ressaltar que a relação entre alegria e tristeza não se faz de forma absoluta, visto que existe toda uma gradação. Assim, não existem encontros absolutos, mas encontros contingentes que se dão nos mais diversos movimentos, compondo as mais variadas linhas. É a ordem de conveniências e desconveniências, a ordem comum. Assim,

\footnotetext{
${ }^{4}$ Mais adiante, veremos que essas composições, fruto dos encontros, não se fundem em visão maniqueísta, através do estabelecimento fixista do que é considerado bom ou ruim, mas decorrem das possibilidades da potência da própria vida.
} 
vê-se que essas linhas, enquanto fluxos intensivos e enquanto portadoras de potências expressivas e interrogativas, vivem num constante estado de experimentação: vê-se que elas experimentam a si mesmas nos encontros por elas provocados ou nos encontros que lhes são impostos por outras linhas da diferença em ação, linhas constitutivas disto ou daquilo, constitutivas deste ou daquele signo, deste ou daquele acontecimento, ou até de um novo tipo de relação esportiva com as águas, com o ar etc.” (ORLANDI, 2000, p. 49).

Agora, é sobre os movimentos da vida que precisamos falar, porque, se quisermos avançar na desantropologização do mundo e dos sentidos, teremos de perceber as problemáticas que estão envoltas em torno dessa noção.

\section{LIBERAÇÃO DA POTÊNCIA ANIMAL E VEGETAL}

O fenômeno da atomização do social ou da crescente psicologização do mundo que já vimos leva ao aguçamento do individualismo. Com isso, há todo um embaralhamento das fronteiras entre público e privado, que começou a ser forjado na Grécia antiga e se agudizou na modernidade, com a revolução Industrial e a separação bem demarcada entre local de trabalho e local de desdobramento da vida privada (a casa).

Para o grego, a vida privada era uma espécie de resto que tinha de ser controlado, pois representava o que era considerado de mais baixo, vista como condição niveladora, que igualava o ser humano aos outros animais. A condição de assimetria dos gestos e comportamentos não era bem vista. A civilidade de cariz etnocêntrico não parou de tentar controlar os impulsos, as pulsões ou tudo que nos remetesse a uma espécie de condição animal, como nos mostra Elias (1994). Um bom exemplo é todo o cuidado culinário que se dispensa na preparação dos animais. "Em muitos de nossos pratos de carne, a forma do animal é tão disfarçada e alterada pela arte de sua preparação e trincho que, quando a comemos, quase não nos lembramos de sua origem” (ELIAS, 1994, p. 127-28).

Então, a própria relação com o corpo, os corpos mediados nos espaços públicos e nos privados, passará por toda uma grade de significações, de práticas de proibição e de liberações, que serão reforçadas e apreendidas através do fazer educativo, visto que as estratégias e medidas adotadas para cercar e "controlar" o contato que se tem com os prazeres são dependentes de uma conduta regrada, instaurada na dependência com o princípio racional ou lógico. Assim, as grades de significações e seu alcance prático são revestidos de estratégias e princípios que possuem uma finalidade ou uma razão. Então, o uso dos prazeres e a conduta racional serão conectados através do ensino das práticas 
tidas como civilizadas, fazendo com que "o padrão social a que o indivíduo fora inicialmente obrigado a se conformar por restrição externa é finalmente reproduzido, mas suavemente ou menos, no seu íntimo através de um autocontrole que opera mesmo contra seus desejos conscientes" (ELIAS, 1994, p. 134-35).

Logo, a educação de cariz ocidental também pode ser considerada como um espaço produtor e reprodutor de uma tripla topografia que cria e recria a relação dicotômica, dinâmica, tensiva, paradoxal e de interdependência entre diversos domínios: divino versus mundano; natural versus cultural; animal versus humano ${ }^{5} \mathrm{e}$, assim, ajuda a formar a configuração de um mundo possível, assentado no antropocentrismo.

Fazendo isso, a educação ajuda a reforçar, mas também poderá ser utilizada para problematizar e transformar as demarcações ontológicas, sociais e culturais que constituem o mundo como o conhecemos, nos fazendo acreditar na existência de certa constância e permanência, nos defrontando, assim, com o já instituído. Nesse processo, a educação reforça e fortalece o raio antropocêntrico, colocando como inferior, subalterno e marginalizado todo e qualquer tipo de vida ou fenômeno que não seja o especificamente humano ou que não ajude a reforçá-lo. Diante disso, “os animais selvagens, por sua vez, nas zonas não cultivadas, estão fora dessa relação e manifestam essa exclusão comendo a carne crua de seus semelhantes" (MUNIZ, 2015, p. 20). Assim, a formação do habitus comedido e controlado, que se apresenta de forma mais intensa nos espaços públicos, dependerá do aparato institucional.

Portanto, uma das possíveis liberações que já podemos antever, diz respeito ao mencionado esboroamento entre as esferas do público e do privado, uma vez que, nas ciências sociais, já é consenso afirmar que hoje há uma demasiada ênfase na esfera privada, que, desde a Grécia antiga até meados da modernidade, não parou de ser vigiada e regrada, porque era tida como perigosa, pois portadora de certa potência, certo devir animal, que remeteria ou suplantaria a humanidade a certa condição de natureza, que teria de ser controlada.

Acontece que, com a atual desmesura dos princípios que antes estavam apenas associados aos cuidados da Oikos (vida privada), tem-se uma liberação da vida animal e vegetal que antes estavam postas sob os controles das regras e comportamentos associados à civilidade e ao jogo da cidadania da Ágora (vida pública). Também é importante assinalar que o pensamento feminista contribuiu nessa

\footnotetext{
${ }^{5}$ Explicamos essa tripla fronteira no livro O sabor dos Saberes, lançado em 2016, pela editora Multifoco. Agora, não é o caso de voltarmos a tratar dela, mas apenas de evidenciar como a educação, de cariz etnocêntrico, está comprometida com a criação das pulsões que são consideradas baixas, justamente pelo fato de remetê-las ao que é considerado da ordem do animal e do natural.
} 
desarticulação, a partir do momento em que desmascarou a instância pública como espaço não representativo das mulheres e da condição feminina, pois, desde o início, a Ágora fora criada como espaço de representação em que apenas homens considerados gregos poderiam participar. A democracia já nasceu elitista. Também a Oikos sempre consistiu, não só na casa propriamente dita, mas em terras e bens, assim como toda uma esfera de atividades, que estavam sob o comando dos homens (FOUCAULT, 1984). Além disso, "essa atividade é útil a toda a cidade porque contribui para a sua riqueza e, sobretudo, porque lhe fornece bons defensores: o proprietário de terra, habituado aos rudes trabalhos, é um soldado vigoroso e os bens que possui fazem-no interessar-se em defender corajosamente o solo da pátria" (FOUCAULT, 1984, p. 138).

Assim, atualmente, assistimos à potencialização de uma série de excluídos, incluindo: as mulheres, a natureza (o meio ambiente para os ecologistas, o Mundo para Serres), o animal, o vegetal etc. É por isso que Deleuze e Guattari (1995) nos mostram a importância de reestabelecermos o contato com o plural e com o duplo ao que está posto, nesse caso, o devir-mulher, devir-puta, devirbicha, devir-animal, devir-vegetal etc.

Com isso, podemos dizer que o devir-vegetal e o devir-animal foram liberados. Eles têm muito a nos dizer, nos ensinar. A aprendizagem agora se transforma, porque se dá na complexidade e desestabilização de esferas e reinos que estavam postos, vistos de forma estáveis, compondo relações dinâmicas e tensivas, de forma simples e simplificadas. Atualmente, já não podemos mais dizer que o único tipo de vida qualificada é a vida humana, sob risco de incorremos em demasiado simplismo e sob risco de agudizarmos uma crise ecológica que já se encontra avançada. Os últimos relatórios de especialistas mundiais são alarmantes.

\section{VIDA E APRENDIZAGEM}

Nesse contexto, "a vida passou a se constituir no elemento político por excelência, o qual tem de ser administrado, calculado, gerido, regrado e normatizado" (DUARTE, 2010, p. 226). Assim, em tempos de biopolítica, podemos afirmar que um dos principais produtos dos dispositivos curriculares é sempre a criação e potencialização de mais-vida. Esse fenômeno tem reverberação em toda formação das sociedades contemporâneas, visto que "quando se torna impossível discernir entre bíos e zóe, bem como entre política e ciências médico-biológicas, surge uma época em que a intervenção médica é política e a ação política é médica e biologizante” (DUARTE, 2010, p. 230-231).

Nesse novo cenário, viver quase se torna sinônimo de aprender. Podemos perceber essa sinonímia de forma madura na teoria do conhecimento de Maturana (2001), visto que, para ele, a 
característica distintiva que separa os seres vivos dos inanimados é justamente a capacidade de processar informação. Esse autor nos oferece um exemplo esclarecedor sobre o processo de metabolização das células presentes nos organismos vivos, além disso, ele amplia a noção de aprendizagem. Segundo ele,

o que se tem que enfatizar é algo que os educadores sabem: que a aprendizagem tem a ver com o modo de vida. A palavra aprendizagem vem de apreender, quer dizer, pegar, ou captar algo. No entanto, de acordo com o que eu lhes disse, a aprendizagem não é a captação de nada: é o transformar-se em um meio particular de interações recorrentes. Quando se entra para a universidade para estudar algo, entra-se em um certo meio e vai-se transformando com esse meio. É tão claro que isso seja assim, que a pessoa sai por uma porta diferente daquela pela qual se entra. Interessante. Como eu sei que é uma porta diferente? Claro, a porta parece ser a mesma, mas a forma como tratam a pessoa é diferente, A pessoa é diferente e o lugar é diferente. A pessoa vai mudando com o lugar. Mas se a pessoa assume isso, então a aprendizagem tem a ver com viver esse domínio. Parte do viver esse domínio pode estar no discurso, mas essencialmente tem que estar nas coordenações de ação que constituem esse domínio (MATURANA, 2001, p. 84).

Esse novo modo de se conceber a aprendizagem, o conhecimento e a vida de forma geral são recentes, pois, durante muito tempo, a educação clássica compreendia o processo de aprendizagem de forma muito circunscrita e limitada, muitas vezes, associando-a aos muros da escola. Além disso, a aprendizagem era vista como processo que se desenrola exclusivamente através da relação entre professor-aluno. Isso também acontecia com o mundo do trabalho, visto que, durante muito tempo, o mesmo era reservado a poucos e possuía um status completamente negativo.

Assim, temos que, no cenário da educação clássica, o devir da aprendizagem era bastante dependente das gerações, visto que nem todos precisavam aprender o tempo todo, além disso, ainda existia a crença de que os adultos chegariam em um momento de maturidade, em que se alcançava um certo estado de "perfectibilidade". Nesses moldes, o professor é visto como o único responsável pelo ensino, o detentor do conhecimento. Já o aluno é visto como um ser sempre inconcluso, pronto a ser "preenchido pelos saberes", que, na maior parte das vezes, é condensado e professado através de um currículo etnocêntrico e extremamente centrado nos conhecimentos pretensamente científicos. Ao aluno, visto como sujeito "sem luz", é negado qualquer compartilhamento de experiências e saberes, dada sua condição de inacabamento. Nessa perspectiva, saberes são invisibilizados, uma vez que na lógica da colonialidade do saber, vale apenas o conhecimento de quem ensina, nesse caso, o professor. Esse tipo de compreensão invalida os processos de ensinagem que são processos 
biounívocos de troca de saberes, ou seja, a tarefa de ensinar não caberia tão somente ao professor, mas também ao estudante. A admissão desse tipo de relação reforça a construção de saberes na sua condição de devir, e, portanto, sem protocolos coloniais de ensino e aprendizagem, questionando, desse modo, o estabelecimento de domínios essencializados entre quem ensina e quem aprende.

Seja como for, hoje, as coisas mudaram, pois vivemos em uma época que "distingue-se pelo lugar central ocupado pelas aspirações de bem-estar e pela busca de uma vida melhor para si mesmo e os seus" (LIPOVETSKY, 2007, p. 16). Então, parece que podemos afirmar, com Pelpert (2009, p. 13), que hoje é a vida que serve como ponto de apoio último para novas lutas e reivindicações individuais e coletivas, pois "nunca o capital penetrou tão fundo e tão longe no corpo e na alma das pessoas, nos seus genes e na sua inteligência, no seu psiquismo e no seu imaginário, no núcleo de sua 'vitalidade"'.

O que parece é que já estamos diante da operatividade de um biocurrículo, em que a problematização entre educação e vida, dos cuidados que se tem com o corpo e, de modo geral, do cuidado sendo alçado a um dos principais eixos que ajudam a nos formar têm de ser levados em conta, sob o risco de esses processos passarem despercebidos, e sob o risco de continuarmos naturalizando o corpo e seus processos fisiológicos característicos, não percebendo que, a partir desse contexto, ele também se tornou uma questão política.

Assim, de todo modo, estamos diante de uma economia e política curriculares. Estamos diante da emergência de um fenômeno que transformou os fenômenos fisiológicos em questões políticas. A insistência e a forma como isso ocorre hoje são questões inéditas na história do ocidente. O corpo, tomado como questão política e curricular, eis mais uma problemática que temos de enfrentar.

Retomando a tese de Maturana (2001), de que uma das características distintivas da vida é a capacidade de aprendizagem, notamos um importante deslocamento da concepção antropocêntrica à biocêntrica, pois, se antes o ser humano era visto como o portador legítimo, o guardião da cultura, agora ele tem de dividir essa condição com todos os outros seres viventes. O antigo acoplamento duro, fruto de uma dialética dual, que se apresentava através da exclusão do Mundo e se apresentava a partir dos movimentos assimétricos (SERRES, 2009), perde força e está sendo substituído por relações simétricas, em que "as coisas da Terra e da vida, dizem elas, codificadas como nós, sabem e podem receber informações, emiti-la, armazená-la, tratá-la” (SERRES, 2009, p. 80).

Assim, o mundo se apresenta de forma complexa, plural, através de uma entropia que não se deixa conter-se pela sanha de controle do ser humano. Com isso, faz-se urgente tentativas de se 
aprender sob inspirações ontológicas e ecológicas, porque é imperioso e imprescindível aprendermos a habitar um lugar comum.

\section{CONSIDERAÇÕES FINAIS}

O que devemos aprender do devir é que ele sempre devém. Ele encontra-se sempre em estado de fuga, de vazamento, não se sujeitando a protocolos criados e engessados por nós mesmos nem tão pouco por normas advindas de outros contextos socioculturais. Com isso, podemos conjecturar que a aprendizagem, na perspectiva do devir, não significa mais acumular, reter, mas, ao invés, evadir, transpor. Isso nos diz muito sobre a constituição de fronteiras ou domínio dos próprios, sobretudo porque ocorre uma inflexão importante em nossa formação que facilmente resvala em processos de territorialização e delimitação, pois, ao invés de priorizar em demasia esses mecanismo e processos, eles passarão a colaborar com os fenômenos de desterritorialização e fuga, na composição dos espaços-tempos, propícios ao florescimento dos encontros.

Então, se eles remetem à composição do espaço e dizem respeito à criação de tempos, já estamos falando sobre o currículo, porque vimos que esse pode ser compreendido como um potencializador de encontros, ao passo que a própria educação se transforma em possibilidade de se fazer acontecer esses encontros.

E, pensando na ética dos encontros bons e ruins, podemos conjecturar que os encontros bons se caracterizam pelo aumento da potência de vida, pelo fato de estarem envolvidos em tonalidades afetivas, que nos trazerem alegria. Já os encontros ruins podem ser vistos como aqueles que estão implicados em tonalidades afetivas opostas, como a tristeza. Porém, o diálogo de Deleuze com Espinosa (1981) nos mostra que não existe estado absoluto de nenhuma dessas tonalidades, afinal, elas estão imersas na lógica da imanência, uma lógica mundana, contingente, que se encontra sob o signo da precariedade.

Como vimos, os saberes situados nos abrem à diversidade, ajudando a nos situar em um mundo sempre se fazendo. Além disso, nos possibilita perceber como a pedagogia, que se dá a partir das brechas das fronteiras, consiste, antes de mais nada, numa antipedagogia, porque, ao invés de buscar visibilizar, fortalecer e legitimar os mecanismos e estratégias de normalização e integração hegemônicos, busca um loci onde esses mecanismos e estratégias só podem existir a partir dos fluxos 
e linhas. Desse modo, os encontros sugerem a capacidade de transitar em contextos diversos em que nos formamos. Qualquer interrupção já é uma violência! Essa antipedagogia, na verdade, consiste mais em um chamamento, porque nos lembra duma pedagogia em seu estado nascente, como nos aponta Serres (1993) ao dizer que:

outrora chamava-se pedagogo ao escravo que conduzia para a escola o filho dos nobres. Hermes acompanhava-o também, por vezes, como guia. A criança abandona a casa de família; saída: segundo nascimento. Toda aprendizagem exige essa viagem com o outro e com a alteridade, mas, durante essa passagem, muitas coisas se alteram (1993, p. 59).

Apreender, nessa perspectiva, não significa mais reter, segurar, depositar, ampliar o domínio, mas: circular, dispor, fluir, seguir rastros, ser-em-devir. Outra coisa que chama à atenção no relato de Serres (1993) é a presença de Hermes. Esta divindade possui várias semelhanças com a nossa divindade Exú. Ambos são mensageiros e caminhantes, são divindades das passagens e estradas, da transformação e invenção. Ambos possuem uma forte ligação com a humanidade, porque é através deles que as mensagens são enviadas, logo, é a partir deles que existe possibilidade de circulação do fluxo, do saber. Nesse sentido, eles podem ser vistos como metáforas, como figuras constituintes do saber. Em um movimento antropofágico, podemos, mesmo, nos apropriar de Hermes enquanto Exú. Assim, Hermes pode ser caracterizado e transmutado como nosso Exú. Nessa versão, o nosso Hermes afro-brasileiro, latino americano, nos mostra que a viagem, o caminhar, as encruzilhadas são de fundamental importância na condição daquele que se coloca disponível e aberto ao aprender. Como figura simbólica do saber e como princípio da transformação, Exú nos envia a uma configuração na qual os próprios saberes se dão na dependência do movimento, nas encruzilhadas e estradas, no próprio processo do caminhar. Não é à toa que, na mitologia afro-brasileira, ele consiste na figura mais controversa e temida. Arte do encontro!

\section{REFERÊNCIAS}

DELEUZE, Gilles. Foucault. São Paulo: Brasiliense, 2006.

Espinosa e o problema da expressão. Ano: 1981. Acesso em: jun. de 2015. Disponível em: http://conexoesclinicas.com.br/wp-content/uploads/2015/12/DELEUZE-G.-Espinosa-e-o-Problemada-Express\%C3\%A3o1.pdf

Proust e os signos. 2.ed. Rio de Janeiro: Forense Universitária, 2003.

Pensamento nômade. In: ESCOBAR (org.). Por que Nietzsche? Rio de Janeiro: Achamé, s/n. 
Deleuze, Gilles; Guattari, Félix. Mil platôs: capitalismo e esquizofrenia 1. São Paulo: Ed. 34, 1995.

DUARTE, André. Vidas em risco: crítica do presente em Heidegger, Arendt e Foucault. Rio de Janeiro: Forense Universitária, 2010.

ELIAS, Norbert. O processo civilizador I. Rio de Janeiro: Jorge Zahar Ed., 1994.

FOUCAULT, Michel. História da sexualidade, 2: o uso dos prazeres. Rio de Janeiro: Edições Graal, 1984.

História da sexualidade, 1: a vontade de saber. Rio de Janeiro: Edições Graal, 1988.

GUATTARI, Félix. As três ecologias. Campinas, SP: Papirus, 1990.

INDOLD, Tim. Estar vivo: ensaios sobre movimento, conhecimento e descrição. Petrópolis, RJ: Vozes, 2015.

LIPOVETSKY, Gilles. A era do vazio: ensaios sobre o individualismo contemporâneo. Barueri, SP: Manole, 2005.

. A felicidade paradoxal: ensaio sobre a sociedade de hiperconsumo. São Paulo: Companhia das Letras, 2007.

MATURANA, Humberto. Cognição, ciência e vida cotidiana. Belo Horizonte: Editora UFMG, 2001.

MUNIZ, Fernando. Prazeres ilimitados. Rio de Janeiro: Nova Fronteira, 2015.

ORLANDI, Luiz B. L. LINHAS OE AÇÃO DA OIFERENÇA. In: ALLIEZ, Eric (org.). Gilles Deleuze: uma vida filosófica. São Pauta: Ed. 34, 2000.

PELPERT, Peter Pál. Vida capital: ensaios de biopolítica. São Paulo: Iluminuras, 2009.

SERRES, Michel. O terceiro instruído. Lisboa/Portugal: Instituto Piaget, 1993.

SERRES, Michel. Tempo de crise: o que a crise financeira trouxe à tona e como reinventar nossa vida e o futuro. São Paulo: Bertrand Brasil, 2009.

TADEU, Tomaz. A arte do encontro e da composição: Spinoza + Currículo + Deleuze. Educação \& Realidade. $\mathrm{N}^{\circ}$, 27(2):47-57 jul./dez.2002. Acesso em: jun. de 2017. Disponível em: http://www.seer.ufrgs.br/educacaoerealidade/article/viewFile/25915/15184

UNGER, Nancy Mangabeira. Da foz à nascente: o recado do rio. São Paulo: Cortez; Campinas, SP: Editora da Unicamp, 2001. 


\section{A EDUCAÇÃO COMO ARTE DOS ENCONTROS}

Resumo: O presente ensaio é estruturado em torno da crítica ao antropocentrismo. Trata-se de uma crítica que problematiza a limitada/restrita construção de mundo que tal princípio nos impõe, pois, sem um rompimento definitivo com o antropocentrismo não é possível liberar a potência da diferença, nos circuitos criativos dos diversos devires e dos novos modos de existência. Em torno disso, a educação e os empreendimentos curriculares, bem como as demandas formativas que se depreendem desses processos, poderão ser de grande valia, na medida em que funcionem como potentes instâncias ontológicas, ecológicas, epistemológicas, existenciais etc., nos ajudando na composição/configuração de novos mundos possíveis. Nesse sentido, a educação torna-se, ao mesmo tempo, um empreendimento crítico e criativo, pois, além de problematizar o existente, ajuda a constituir o novo. Por isso, também consiste num potente mobilizador/criador de existências: de novos modos de vida. Assim, compreende-se que uma das formas de liberarmos a diversidade de modos de vida, na atual aridez que nos encontramos, é resgatar e/ou problematizar a potência dos movimentos que se dão através das possibilidades de encontros, pois o encontro nos mobiliza em relação a um mundo que se encontra sempre em devir.

Palavras-Chave: Educação dos Encontros. Currículo. Antropocentrismo.

\section{EDUCATION AS AN ART OF ENCOUNTERS}

Abstract: This essay is structured around the critique of anthropocentrism. It is a critique that problematizes the limited/restricted construction of the world that this principle imposes upon us, since, without an definite break from anthropocentrism it is not possible to liberate the power of difference within the creative circuits of the various becomings and new ways of existence. Around this, education and curricular entrepreneurship, as well as the formative demands that emerge from these processes, can be of great value, as long as they function as potent ontological, ecological, epistemological, existential, etc. instances, helping us in the composition/configuration of new possible worlds. In this sense, education at the same time, is a critical and creative enterprise, since, in addition to problematizing the existing one, it helps to constitute the new. Therefore, it also consists of a powerful mobilizer/inventor of new ways of life. That said, one understands that one of the ways of liberating the diversity of ways of life, in the current aridity that we find, is to rescue and/or problematize the power of the movements that occur through the possibilities of encounters, because the encounter moves us towards a world that is always in the process of becoming.

Keywords: Education of encounters. Curriculum. Anthropocentrism.

\section{L'ÉCDUCATION COMME UN ART DES RENCONTRES}

Résumé: Cet essai est structuré autour de la critique de l'anthropocentrisme. C'est une critique qui problématise la construction limitée/restreinte du monde que ce principe nous impose, puisque, sans rupture effective avec l'anthropocentrisme il est possible de libérer le pouvoir de la différence, dans les circuits créatifs des diverses bases et des nouveaux modes d'existence. Autour de cela, l'éducation et l'esprit d'entreprise curriculaire, ainsi que les exigences formatives qui émergent de ces processus, peuvent être d'une grande valeur, dans la mesure où ils fonctionnent comme instances puissantes das le domaine ontologique, écologique, épistémologique, existentiel, etc., nous aidant dans la composition/configuration de nouveaux mondes possibles. En ce sens, l'éducation, en même temps, est une entreprise critique et créative, car, en plus de problématiser l'existant, elle contribue à constituer le nouveau. Par conséquent, elle se consistiue également en un puissant mobilisateur/inventeur de nouveaux modes de vie. Ceci dit, on comprend que l'une des façons de libérer la diversité des modes de vie, dans l'aridité actuelle dont nous trouvons, est de sauver et/ou de problématiser le pouvoir des mouvements qui se produisent à travers les possibilités de rencontres, parce que la rencontre nous meut par rapport à un monde qui est toujours en train de devenir.

Mots-clés: Éducation des recontres. Curriculum. Anthropocentrisme. 